O Eixo e a roda, Belo Horizonte, v.24, n.1, p. 61-76, 2015

\title{
A descrição do mundo de Verônica Stigger ou uma antropofagia desidratada
}

\section{Description of Veronica Stigger's world or a dried anthropophagy}

\author{
Ângela Maria Dias \\ Universidade Federal Fluminense (UFF), Rio de Janeiro, Rio de Janeiro, Brasil. \\ angelmdias@gmail.com
}

Resumo: $\mathrm{O}$ ensaio se propõe a interpretar o último relato de Verônica Stigger, Opisanie Swiata, a partir da sua abordagem de Raul Bopp e da antropofagia modernista. Partindo de tal objetivo, o texto procura levantar os recursos utilizados pela autora, a fim de valer-se, na composição da narrativa, do legado de diversos intelectuais e escritores do período em pauta. Nesse sentido, aponta-se, na construção da novela, além da bricolagem de pequenos textos e de ilustrações na estruturação do volume, a importância central do pastiche, segundo é apresentado por Antoine Compagnon, no livro $O$ trabalho da citação. Entretanto, a avaliação do rendimento deste sofisticado trabalho de elaboração textual surpreende uma certa fragilidade crítica pela ornamentalidade das apropriações concatenadas sob o enfoque humorístico, com um tipo de jocosidade leve, de feitio francamente gratuito.

Palavras-chave: pastiche; bricolagem; antropofagia; humor.

Abstract: The essay proposes to present an interpretation of the recent fiction by Veronica Stigger, Opisanie Swiata, and aims to criticize its approach of Raul Bopp and the modernist anthropophagy. Behind the bricolage of texts and illustrations, the work strongly makes use of the 
pastiche technique according Antoine Compagnon in his book Le travail de la citation. However, this sophisticated work of textual elaboration merits a critical evaluation due to the excessive ornamentality of its appropriations gathered under a humoristic focus characterized by a light playfulness frankly groundless.

Keywords: pastiche; bricolage; anthropophagy; humor.

Recebido em 13 de março de 2015.

Aprovado em 17 de junho de 2015.

O último relato de Verônica Stigger, embora aponte numa direção mais ampla, conforme promete o próprio título, estrutura-se por fragmentos e pequenos textos de natureza diversificada, justapostos e concatenados por um rarefeito nexo narrativo que se equilibra na viagem do pai polonês ao encontro do filho doente e recém-descoberto.

Seu parentesco com o experimentalismo modernista da década de 1920 é óbvio, no que se apropria de uma comicidade leve e piadista, além da composição partida, sintética e descontínua.

O enredo reúne, numa pauta lúdica, Raul Bopp, o poeta brasileiro, autor do célebre poema Cobra Norato, e Opalka, o pintor conceptual franco-polonês, autor de uma série denominada Opisanie Swiata (que significa "Descrição do Mundo"), como dois viajantes que, ao se terem conhecido na partida da Polônia ao Brasil, resolvem ir juntos para a Amazônia. A amizade que se desenvolve ficcionalmente talvez aluda à afinidade entre ambas as personalidades que, em vida, dedicaram-se, cada um à sua maneira, a perseguir o infinito e assim procederam artisticamente às respectivas descrições do mundo.

Bopp, participante da ebulição modernista, e, sobretudo da Antropofagia, na qual foi um dos ativos organizadores, é conhecido por sua vocação itinerante de incansável desbravador do Brasil e do mundo, e não se poupou na composição de inúmeros relatos de viagem. Opalka, por sua vez, dedicado a presentificar através da pintura a ideia do infinito, transforma seu trabalho artístico num destino espiritual, ao exercitar a meditação sobre o tempo pela contagem sequencial de números em telas sucessivas, os 233 "detalhes" (segundo as denominava o autor), só interrompidos por sua morte em 2011. 
Talvez se possa aproximar também, a partir desta parceria nuclear, a poeticidade plástico-musical e o telurismo do Cobra Norato, insistentemente emendado pelo autor, em sua personalidade irrequieta, à determinação de Opalka, na espacialização da passagem do tempo, retomada pela composição de cada novo "detalhe", em busca de um ponto de fuga infinito. A descrição do mundo como espaço percorrido no "desesperadamente verde" da Amazônia, em sua epicidade intuitiva e constantemente enriquecida, pode ser a outra face da insistente sequência de números de Opalka em sua coleção de pedaços seriados para plasmar a meditação da passagem do tempo.

A viagem como processo de formação dos "olhos livres" inerentes ao primeiro modernismo dos anos de 1920, nesta sua versão do século 21 , ganha um perfil reciclado. A diversificação qualitativa dos fragmentos, com textos de diferentes naturezas e procedência, - como cartas, anúncios anacrônicos, trechos de um guia antigo de viagem, narrativas em primeira e terceira pessoas -, sugere, numa espécie de mise en abyme, constituir o relato da viagem de Opalka, que, na última cena do livro, senta-se na casa do filho morto, para escrever suas recordações da travessia até o Brasil.

A bricolagem da narrativa, ao recolher citações literais combinadas a pequenas histórias autorais, concatena-as a pastiches, numa conjugação minimalista de partes que dá ao todo, um clima leve de brincadeira inconsequente e de piadismo infantil.

A primorosa edição do volume em roxo e dourado, com páginas de tom pastel, de tonalidades variando do lilás forte, ao claro e ao bege rosado, traz muitos hiatos entre seus capítulos minimalistas que se sucedem entre pequenas frases assertivas sobre procedimentos de viagem e reproduções de reclames contemporâneos ao enredo, que é passado na década de 1930 e se conclui com a invasão nazista da Polônia, em 1939. Os aconselhamentos são oriundos de um guia turístico antigo que, no início da narrativa, será oferecido por Bopp a Opalka, e se justapõem à maioria dos episódios que possuem diferentes configurações. Podem ser cartas, trocadas entre pai e filho, durante a longa jornada do primeiro ao Brasil, ou ainda as próprias narrativas da viagem, escritas em primeira e em terceira pessoa, que o leitor poderá, ao final da leitura, atribuir a Opalka.

Depois do relato concluído, imediatamente justaposto a ele, a autoria do livro revela-se na apresentação de uma listagem bibliográfica 
de fontes de composição intitulada "Deveres" que abarca desde livros, artigos diversos, a maioria sobre os modernistas de 1922, até referências a conversas com pessoas variadas, desde o próprio marido da autora, a parentes próximos, amigos e conhecidos em momentos esporádicos.

O desnudamento do processo de composição não é absolutamente um procedimento original. Desde o alto modernismo, a autoconsciência da forma constitui um padrão instituído de apropriação crítica do fazer criativo. No entanto, aqui, como gostaria de demonstrar, o recurso metacrítico não aposta em qualquer ponto de fuga reflexivo, mas ocupa-se prioritariamente com a sua economia interna, no sentido de satisfazer-se com o cultivo da engenhosidade que lhe é própria.

Terry Eagleton, no artigo "Capitalismo, Modernismo e PósModernismo", ao partir da conhecida postulação de Jameson sobre o pastiche, como modo característico da cultura pós-moderna, em detrimento da paródia, sugere que, apesar da excelência do argumento, a atualidade não é completamente estranha à paródia mas, ao contrário, "com sua dissolução da arte nas formas predominantes de produção de mercadorias", ocupa-se em parodiar "a arte revolucionária de vanguarda do século XX" (EAGLETON, 1995, p. 53). A asserção, no caso desta obra de Stigger, sobre a viagem na acepção dos modernistas de 1922, em seu empenho em descobrir o Brasil e desvelá-lo critica e criativamente, tem algo a ver.

Na medida em que elege Raul Bopp, e sua incansável vocação desbravadora de espaços e latitudes, o livro busca encenar a importância do tópico por meio de um dos seus personagens exemplares. Nesse sentido, "Deveres" lista uma expressiva quantidade de livros sobre viagens das mais variadas autorias: O turista aprendiz de Mário de Andrade, o Serafim Ponte Grande de Oswald de Andrade, diversos relatos de viagem de Raul Bopp, A grande aventura nos confins da Amazônia de Flávio de Carvalho, além de inúmeros outros autores como Wes Anderson, Frei Gaspar de Carvajal, Maria Martins, Lévi-Strauss e outros ainda.

Entretanto, apesar de aplicar-se consideravelmente em conhecer o protagonismo de Bopp e as implicações das viagens, pela diversidade da recolha bibliográfica, esta obra de Stigger trata do tema da travessia internacional na direção dos trópicos de maneira leve e descontraída, num franco despojamento de qualquer preocupação mais crítica ou de intenção polêmica em torno dos ideais utópicos modernistas. O livro, 
como objeto é peça primorosa, bem acabada, com cores, tipos, fotos e ilustrações numerosas, de profundo bom gosto. No entanto, ao fim e ao cabo, o leitor tem acesso a uma obra risonha e brincalhona, com o toque do final melancólico, pela dedicatória paterna do relato ao filho morto.

Aqui, a verdade do percurso é uma enfiada de danças, brincadeiras, conversas e algazarra tipicamente turística, com toques de fantasia exótica pelas inúmeras alusões a lendas e superstições - como, por exemplo, a existência de sereias - ou ainda a motivos e fabulações amazônicas, como a cobra grande, e pequenas historietas sobre a floresta e seus habitantes.

Do meu ponto de vista, o interesse do relato reside, sobretudo, na prática do recorte e da colagem da citação. Segundo Antoine Compagnon, tais experiências infantis constituem o fundamental objetivo da leitura e da escrita, como "formas derivadas, transitórias e efêmeras" desse jogo. Segundo o teórico, "a lembrança dessa prática original do papel, anterior à linguagem", é responsável pela "alegria da bricolagem" em função do "prazer nostálgico do jogo de criança” (COMPAGNON, 1996, p. 13). Na progressão desse raciocínio, toda "leitura já procede de um ato de citação" (COMPAGNON, 1996, p. 14), na medida em que quando leio, "cito, extraio, mutilo, desenraízo" (COMPAGNON, 1996, p. 13). Por isso, segundo o mesmo ensaio, o autor lembra que Quintiliano "valia-se disso para explicar as vantagens da leitura sobre a audição", justamente pelo fato de que, a primeira experiência "é livre e não é obrigada a acompanhar o orador” (QUINTILIANO apud COMPAGNON, 1996, p. 14).

E se, ainda segundo Compagnon, toda "leitura repousa em uma operação inicial de depredação e de apropriação de um objeto que o prepara para a lembrança e para a imitação, ou seja, para a citação" (COMPAGNON, 1996, p. 14), o livro de Stigger, com a sua lista de "deveres", ao final, não faz outra coisa além de teatralizar a própria construção como um ato de leitura, a leitura da viagem numa espécie de réplica jocosa da herança antropofágica.

O ensaísta francês, na sua obra sobre $O$ trabalho da citação argumenta também que é inerente à escrita reportar nela mesma "uma paixão da leitura", porque é esta última que produz a citação. E nesse sentido, "toda escrita é colagem e glosa, citação e comentário" (COMPAGNON, 1996, p. 29) e a citação, porque "objeto extirpado e enxertado" (COMPAGNON, 1996, p. 25), "une o ato de leitura ao de escrita" e, nisso, repete "o gesto arcaico do recortar-colar"(COMPAGNON, 1996, p. 31). 
Entretanto, por seminal que seja, a citação não possui sentido próprio, desligado do texto que a acolhe e a dinamiza, porque não há sentido sem o trabalho do texto (COMPAGNON, 1996, p. 35). Por isso mesmo, "a citação constitui um polo estratégico" não apenas porque está em meio a uma inter-relação de poderes ou sentidos que se cruzam, contaminam e diferenciam no fenômeno do texto (COMPAGNON, 1996, p. 41), mas, sobretudo porque existe "desde o nascimento da linguagem", quando a criança imita a mãe buscando a sua atenção, ou seja, como "um ato de fala elementar e primitivo", na origem de todas as espécies retóricas de repetição (COMPAGNON, 1996, p. 42, 43).

A importância da citação nessa obra de Stigger não reside apenas na provocação intelectual, numa espécie de desafio ao leitor para uma tarefa detetivesca, mas também constitui recurso nuclear para a aquisição de uma perspectiva um pouco mais integrada de sua estrutura fragmentária e da relativa heterogeneidade das partes. Por isso mesmo, a compreensão de sua natureza importa para a progressiva conquista de um posicionamento crítico face às operações autorais.

Nesse sentido, ao basear-se no paralelismo entre figuras de palavras e figuras de pensamento, tradicional na retórica, Compagnon considera dois tipos de citação, a repetição de pensamentos e a repetição de palavras (COMPAGNON, 1996, p. 57). O texto é estruturado basicamente com a citação de palavras, já que, na narrativa dos variados eventos, por sua franca visualidade, se utiliza de empréstimos cuja natureza é basicamente descritiva e não conceptual.

A maioria das citações encontradas é surpreendida, em sua literalidade, e é processada como encaixe ao discurso da enunciação, de maneira coerente e harmoniosa. Ou seja, constitui apropriações cuja origem pode ser percebida, no cotejo com as obras mencionadas na seção "Deveres", ao final.

A esse respeito, talvez seja interessante lembrar que Compagnon considera o processo de apropriação como um sintoma, no qual o objetivo do sujeito da enunciação seria menos tomar de outrem, que empreender uma busca de si "no desfile dos objetos que o retêm tanto ou mais do que eles são retidos" (COMPAGNON, 1996, p. 91). Nesse sentido, a ornamentalidade de grande parte dessas apropriações tem a ver com a construção do personagem Bopp, por Opalka, o amigo de viagem-narrador que, por fim, dedica seu álbum de recortes e souvenirs de viagem ao filho recém-falecido. 
No intuito de esclarecer a fisionomia geral do pastiche, como princípio de construção formal, é importante que se proceda ao exame de alguns extratos significativos do entrecho.

A viagem rumo aos trópicos é feita de navio e, antes de embarcarem, os dois protagonistas se conhecem, quando esperam o trem para o porto. $\mathrm{O}$ estilo da composição é agudamente visual, concebendo os episódios e os diálogos da trama rarefeita como uma sucessão de quadros animados, assiduamente desenhados com minúcias, na apreensão dos movimentos e das atuações de cada um, frequentemente figuradas numa pauta cômica.

Por exemplo, a aparição de Bopp na estação onde já está Opalka é um esquete, cujo traço cômico reporta-se a uma consagrada tradição de filmes humorísticos, com personagens desajeitados e bonachões. Sua compleição roliça, o jogo de corpo atrapalhado e o acidentado da aparição transformam-no, de saída, num tipo "clownesco":

O tipo era atarracado, braços e pernas como pequenas toras. O rosto, redondo, circundado por grossos fios de cabelos castanho-escuros, cortados na forma de um capacete (...) A parte inferior da barriga protuberante não se continha dentro da camisa vermelho-sangue: saltava para fora por baixo e pelas aberturas entre os botões produzidas pela pressão do corpo roliço sob a justeza do tecido. (...) Embora fizesse calor naquele mês de agosto, trazia sobre a camisa vermelho-sangue e a calça clara de linho um longo quimono de seda espalhafatosamente estampado, que, de tão comprido, arrastava no chão e levava consigo poeira, areia, pedrinhas e toda sorte de detritos que porventura encontrasse pelo caminho. Levava, com esforço, quatro malas de tamanhos diferentes: duas em cada uma das mãos e duas debaixo dos braços troncudos. (...) Ao ver Opalka sentado num dos bancos da estação, lendo compenetrado o jornal, sorriu feliz. Acelerou o passinho, tropeçou na barra do quimono e se espatifou no chão a apenas alguns passos do banco (STIGGER, 2013, p. 23).

A figura de Bopp apresentada, com feição e gestos quase farsescos, vai-se desenhando, pelo relato como o de um homem bem humorado, de bem com a vida, alegre e comunicativo e profundamente investido de um projeto itinerante de conhecimento do Brasil e do mundo em sua 
diversidade. A composição icônica se não tem a ver com o próprio Raul Bopp, descendente de bisavô alemão, abriga também a imagem, que, pelo conjunto de depoimentos é bem dele: a de um homem apaixonado pelos outros mundos, pelas outras pessoas, solidário e pródigo em amizades e contatos.

A bricolagem do relato começa já com a entrada cênica do personagem na estação com seu "longo quimono de seda espalhafatosamente estampado" (STIGGER, 2013, p. 23).

Sérgio Buarque de Hollanda, em seu artigo "Bopp e o dragão" (1996, p. 429-433), conta, com delícia e riqueza de detalhes, as características do "perfil meio mítico do poeta" e amigo Raul Bopp, e, entre outros muitos detalhes, fala sobre "seus meteoros familiares":

Deste - do autor - minha lembrança mais viva será sempre metropolitana e cosmopolita. Surpreendi-o no meio de sua volta ao mundo; a menor, que principiou em Santos, a bordo de um Maru, e passou por Varsóvia, depois de tocar em Capetown, Sumatra e Vladivostok, mas antes de alcançar Havana e La Paz. A maior, já se sabe que foi nas terras do Sem Fim da Amazônia. A colossal moeda de bronze com meia libra de peso, o manuscrito de Cobra Norato, o quimono de legítima seda shin-shung-shah, o chapéu tropical, a caveira pré-histórica para servir de cinzeiro, a Constituição da República argentina ("Artículo primero: no hay artículo primero"), as três latas de caviar "Molossol", um guia turístico How to be happy in Warsaw. Em breve tudo se dissipará, porque o poeta é perdulário e dadivoso. Tudo, menos o quimono comprado em Xangai, que presta serviços à noite porque tem um dragão dourado, bom para espantar espíritos maus (HOLLANDA, 1996, p. 430, destaques nossos).

A visualidade desta novela gráfico-visual salta aos olhos de quem a abre: primeiro, as imagens de Varsóvia, seguidas de duas cartas ao pai, a do médico e a do filho, e finalmente a reprodução da capa com os créditos, isto é, o título do livro e o nome da autora. Só então, na folha seguinte, o leitor entra em contato com o primeiro capítulo que tem exatamente o mesmo nome do guia mencionado por Sérgio Buarque no inventário de objetos do amigo: How to be happy in Warsaw. 
Logo adiante, ainda no âmbito do mesmo capítulo, um segundo segmento em $1^{\mathrm{a}}$ pessoa do singular, desfia a recordação de Opalka sobre Bopp, incansável viajante e, nisso, retoma quase integralmente, com exceção de irrisórios trechos sem maior importância (destacados por mim), o extrato disposto acima no citado artigo de Sérgio Buarque:

Dele, minha lembrança mais viva será sempre metropolitana e cosmopolita. Surpreendi-o no meio de sua volta ao mundo; a menor, que principiou em Santos, a bordo de um Maru, e passou por Varsóvia, depois de tocar em Capetown, Sumatra e Vladivostok. A maior foi nas terras do Sem Fim da Amazônia. (...) Das valises ainda marcadas pelas etiquetas e poeiras da Transiberiana (catorze dias entre Vladivostok e Bjelo-Sjelovskaya), onde foi chamado Lafcádio (lembrança de Lafcádio Hearn, o amigo de exotismos), emergiram aos poucos os meteoros familiares. A colossal moeda de bronze com meia libra de peso, o manuscrito de um longo poema no qual trabalhava (ele tinha lá suas veleidades literárias), o quimono de legítima seda shin-shung-shah, o chapéu tropical, a caveira pré-histórica para servir de cinzeiro, a Constituição da República argentina ("Artículo primero: no hay artículo primero"), as três latas de caviar Molossol, um guia turístico How to be happy in Warsaw e uma quantidade absurda de cadernos de anotação. Em breve tudo se dissiparia, porque o poeta é perdulário e dadivoso. Tudo, menos o quimono comprado em Xangai, que presta serviços à noite porque tem um dragão dourado, bom para espantar espíritos maus. O guia ficou comigo. Eu devia dá-lo a meu filho para quando ele pudesse ir à Polônia me visitar (STIGGER, 2013, p. 30-31).

Como se pode constatar, a apropriação é literal, à exceção de ínfimos detalhes. E como se a autora, antes de conceber sua novela tivesse utilizado como método de composição o livro de Compagnon sobre $O$ trabalho da citação que, já em seu início, observa:

Escrever, pois, é sempre reescrever, não difere de citar. A citação, graças à confusão metonímica a que preside, é leitura e escrita, une o ato de leitura ao de escrita. Ler ou escrever é realizar um ato de citação. A citação representa 
a prática primeira do texto, o fundamento da leitura e da escrita: citar é repetir o gesto arcaico do recortar-colar (...) (COMPAGNON, 1996, p. 31).

Assim, a caracterização de Bopp, em sua estilização como "personagem inesquecível", continua na deriva apropriativa dos muitos depoimentos deixados pelos amigos e enumerados em "Deveres". Num dos segmentos em 1 a pessoa do capítulo "Vai, Priscila, dança a tarantela", a lenda do personagem, dessa feita, mistura as impressões de Menotti del Picchia com as de Plínio Salgado, na afetiva cena da aventura e da disponibilidade existencial da figura:

Bopp é livre como uma flecha disparada de um arco. Já rodou o mundo. Tomou sol. Fincou espinho no pé. Montou a cavalo, remou, bebeu chimarrão, comeu paçoca e viu jacarés de bocas abertas, serrilhadas como o perfil de uma fábrica. Bopp não para. Tem bicho-carpinteiro no corpo (STIGGER, 2013, p. 60).

Confira-se a combinação engenhosa dos dois fragmentos. De Menotti del Picchia: "Viu jacarés de bocas abertas, serrilhadas, como o perfil de uma fábrica. (...) Raul Bopp, acadêmico, é livre como uma flecha disparada de um arco". (DEL PICCHIA apud BOPP, 1968, p. 161). De Plínio Salgado: "Ele é, antes de mais nada, um dos valores mais representativos da mentalidade brasileira. É sujeito viajadíssimo. (...) Andou pra burro. Tomou o sol. Fincou espinho no pé. Montou a cavalo, remou, tomou chimarrão, comeu paçoca e fez outras proezas" (SALGADO apud BOPP, 1968, p. 162).

No penúltimo capítulo "Para não esquecer", mais uma vez a enunciação recorre a outro híbrido, fazendo conviver as expressões de Augusto Méyer, Sérgio Buarque de Hollanda e Jorge Amado:

Bopp será sempre um desses sujeitos cuja vida é muito maior que a obra. Quando acontecia num lugar era sinal de partida imediata. Tinha um cata-vento na cabeça e botas de sete-léguas.

- Aonde vais, Bopp?

— Vou ali e já volto.

Ali: expressão das distâncias. Já: eliminação do tempo. E partia Bopp mais uma vez, para além dos limites comuns, 
para os longes. Há mesmo quem julgue que Bopp nunca existiu. É uma espécie de Pedro Malazartes que entrou para o rol das histórias maravilhosas que as mães contam pra os filhos. Já algumas pessoas me disseram isso. Ficaram admiradas de Bopp existir, pensavam que ele era somente personagem daquelas histórias de viagem que contavam na terra de meu filho. Encontrei, certa vez, um rapaz que, apesar de ter sido companheiro de quarto de Bopp, não acreditava na existência dele. Achava que fosse inventado. Talvez Bopp, ainda vivo, tenha uma biografia assim: $\mathrm{ABC}$ de Bopp e o subtítulo "poeta viajante e pintor de tabuletas" (STIGGER, 2013, p. 146).

\section{Compare-se então, com Augusto Méyer:}

(...)RaulBopp,comedordecaminhos, escoteiroaventuroso, sempre em estado de transe e conjugado no futuro. Tinha um cata-vento girando na cabeça e botas de sete léguas. Quando acontecia num lugar, era sinal de partida imediata. Doente do mal da fuga, tentava escapar de si mesmo, numa corrida louca e desabalada, perseguido pela sombra, aos trancos e barrancos, por este vasto mundo inabitável (MÉYER apud BOPP, 1968, p. 172-173).

E agora, com Jorge Amado:

Há mesmo quem acredite que Raul Bopp não existiu nunca. É uma espécie de Pedro Malasarte, que entrou para o número das histórias maravilhosas, que as mães contam aos filhos. Já algumas pessoas me disseram isto. Ficaram admiradas de Raul Bopp existir de verdade. Pensavam que ele era somente um personagem, daquelas histórias de viagens, que contavam na minha terra. Talvez a atividade consular do poeta tenha agora dado corpo à sua personalidade lendária. Também é possível que outros continuem a pensar que Raul Bopp não existe mesmo e que, esse negócio de Consulado no Japão foi mais uma aventura do novo Malasarte, que, eu juro, será um dia cantado nos A B Cs populares da Bahia (AMADO apud BOPP, 1935, p. 159-160). 
Finalmente, com Sérgio Buarque de Hollanda: "Em Berlim pudemos arrancar-lhe, o cônsul Ildefonso Falcão e eu, a promessa de que ficaria. Ficará mas não antes de dar mais umas voltinhas "Vou ali, já venho"' (HOLLANDA, 1996, p. 430).

A temática da viagem, embora constitua uma questão geracional no modernismo de 1922, ao significar travessia entre visões de mundo e condição de possibilidade da renovação de uma perspectiva de leitura do próprio país e suas tradições, pelo intelectual brasileiro, aqui, nesta novela de Stigger, se transforma apenas na peculiar inclinação de Bopp, como personagem pitoresco, em suas idiossincrasias itinerantes.

Sua individualidade empreendedora e vibrante, sua experiência da vastidão amazônica, suas andanças infatigáveis ganham uma cor exótica, sem que, o enredo se interrogue sobre o possível sentido do deslocamento, no âmbito de uma tomada antropofágica do outro e do mundo, à luz do atual espaço globalizado.

Ao invés disso, o quebra-cabeça de citações encadeadas e integradas com habilidade ao corpo do texto, constitutivo do estilo leve e bem fornido de indicações descritivas, se dispõe a oferecer ao leitor o relato de uma viagem transatlântica que inclui um percurso de trem, na Europa, e a navegação até a Floresta Amazônica, como um roteiro de brincadeiras, passatempos e interações divertidas.

Assim, no trem, a jovem Priscila, mordida pela aranha, na queda de um pote de vidro que continha o animal, dança a tarantela, ao replicar a cozinheira de Oswald, convocada por ele, numa de suas festas, para dançar o "Marimbondo", como se tivesse o corpo picado (BOPP, 2012, p. 28).

No navio, três crianças e uma cachorrinha, em uma de suas travessuras, detidamente descrita, constroem, aos poucos, uma imensa pandorga, que, no hibridismo dos seus materiais, conforma o corpo de um elefante desengonçado, pairando "imponente e frágil", sobre o convés do navio (STIGGER, 2013, p. 96). Trata-se certamente, de uma homenagem ao poema drummondiano, que fala do cotidiano recomeçar da busca de seu avatar, "faminto e tocante" (DRUMMOND, 1967, p. 168).

Pouco antes, os passageiros curiosos e expectantes reuniramse apinhados no convés para presenciar a "aparição de uma sereia em alto-mar" (STIGGER, 2013, p. 76) que, afinal, não passava de um corpo feminino boiando de bruços, em decomposição.

Mais adiante, algumas passageiras descobrem, em plena cozinha, outros entretidos em jogos sexuais com elementos da tripulação, e saem a contar a novidade aos companheiros de viagem. 
Um rito coletivo envolvendo todos os figurantes vai ocorrer na passagem da linha do Equador, quando os neófitos na travessia entre o norte e o sul são convocados a submeter-se a um batismo. Ao final do episódio, na aurora do dia seguinte, já findas todas as provas de iniciação, o navio é cruzado por El Durazno, a nave comandada pelo personagem Pinto Calçudo que, em Serafim Ponte Grande, abriga a "humanidade liberada", e, em permanente itinerância longe dos portos, protesta contra "a coação moral da indumentária" e "a falta de imaginação dos povos civilizados" (ANDRADE, 1978, p. 263-264).

Como se pode constatar, a sucessão de pequenos eventos, entremeada por dizeres do guia anacrônico de turismo à América do Sul e belas fotos de navios e reclames dos anos de 1930, busca retomar o clima de utopia, esperança e alegria da vanguarda antropofágica, mas carece de sua temperatura provocativa.

A "paisagem dilatada de horizontes livres" (BOPP, 2012, p. 11) do Bopp, companheiro de viagem de Opalka aqui, é reduzida ao perfil curioso de um "personagem inesquecível", o que vem a ser uma simplificação da personalidade irrequieta e estimulante do poeta Raul Bopp, agitador cultural, e participante de importantes iniciativas, como o Verdeamarelismo e a Antropofagia.

Num de seus balanços sobre as consequências do manifesto oswaldiano, de 1928, o poeta, aliás, reconhece que o movimento "com suas sátiras audaciosas, provocou uma derrubada de valores, de mera casca literária, sem cerne. Sacudiu hierarquias inconsistentes. Assinalou uma época" (BOPP, 2012, p. 9).

Silviano Santiago, em "O começo do fim", observa que, em sua aliança com o construtivismo, a antropofagia assenta-se "em sólida plataforma ética" e "leva o escritor a desenvolver o gosto pelo lento e paciente trabalho de arte (...) que não é desassociado do trabalho crítico" (SANTIAGO, 2008, p. 21, 18). Nesse sentido, a antropofagia, de um lado, na mesma direção das vanguardas históricas, aponta para uma relação alternativa entre a arte erudita e as culturas de massa, e, de outro, visa negar as estéticas românticas da sinceridade do eu, em nome do artifício e da visão do processo criativo como construção (SANTIAGO, 2008, p. 24).

O trabalho de Veronica Stigger, ao fundar-se na prática incorporadora da citação, adota explicitamente a vocação construtiva, também pela cuidadosa edição do livro como um objeto de luxo, que alia paisagens e publicidade de época ao fragmentarismo eclético do texto segmentado, entre o diário de viagem e a inclinação epistolar. 
Entretanto, ao encetar um diálogo com a literatura modernista de 1920, permanece na leveza da brincadeira simpática, e exime-se de fitar o desafio antropofágico, com olhos contemporâneos. Trata os emblemas e mitos levantados pelas jornadas modernistas, na investigação de um país insuspeito, por meio de recursos que Jameson descreve como característicos do filme de nostalgia, alheios a uma abordagem genuína de sua historicidade.

Assim, aborda o nosso legado modernista, concentrado na figura de Raul Bopp, "através da conotação estilística", apresentando a "anterioridade" como "o brilho falso da imagem", isto é, pela superfície de uma prosa ágil, descritiva e dinâmica. Nesse sentido, determinadas tópicas - a exemplo da cobra grande e da nave "El Durasno", ou do "lado debaixo do Equador" - transformam-se em "moda" ou, como diz o teórico americano, ao citar Barthes, viram-se em "conotação", entendida como "a sondagem das idealizações imaginárias e estereotípicas" (JAMESON, 1996, p. 47) de uma determinada época.

Daí que a “" intertextualidade" como característica deliberadamente urdida do efeito estético e como um operador de uma nova conotação de "anterioridade" e de profundidade pseudo-histórica" (JAMESON, 1996, p. 47), toma a história dos estilos estéticos como estilização bem humorada.

Deste modo, a perspectiva dos brasileiros viajantes - informada pelos influxos vanguardistas responsáveis pelo primitivismo dos anos de 1920 - passa a ser a "descrição do mundo" de Opalka, o polonês, na viagem de retorno ao Brasil para conhecer o filho cuja existência desconhecia. Talvez por esse ponto de vista estrangeiro, as tópicas de Raul Bopp se empalideçam e, despidas de seu antigo poder rítmico e impressionista, de delírio onírico e mal assombrado, não passem de motivos exóticos e graciosos, soando a um anacrônico telurismo.

Entretanto, o principal entrave à criticidade da abordagem do legado de Bopp e da antropofagia, neste caprichado volume que os embala para presente, consiste na ausência de clivagem entre enunciado e enunciação. Ou seja, a falta de um distanciamento irônico entre a estilização dos materiais, como clichês turísticos de um risonho álbum de viagens, induz o sujeito da enunciação a tomar a sério o que o enunciado conta e, sobretudo a ratificar a sua forma de contar. Assim, isentas de qualquer desconfiança, as matérias clicherizadas ganham uma configuração jocosa e humorística, satisfeitas de si e de bem com a vida. 
Braços dados, a enunciação e o enunciado não cometem qualquer "distorção performativa" e assim, pela harmonia de ecos, compõem a paisagem saudosista do percurso de um pai melancólico e reconciliado com a morte do filho que não conheceu, talvez devido à mágica proximidade da floresta.

Opalka retornou à casa do filho. Era ali que ficaria pelos próximos meses ou talvez pelos próximos anos ou ainda, quem sabe, para sempre. Cabisbaixo, com os ombros caídos, apalpou os bolsos do paletó à procura de chave e acabou encontrando o caderninho preto que havia pouco Bopp lhe dera. (...) Remexeu os outros bolsos atrás da chave, que encontrou na parte de trás da calça. Abriu enfim a porta e se viu novamente na pequena sala da casa do filho. Cheirava a mato, e Opalka gostava disso. Aspirou fundo como se quisesse botar para dentro de si todo o ar do ambiente (STIGGER, 2013, p. 148).

Talvez por isso, Flora Sussekind tenha comentado, nas orelhas do volume, que a obra seria a "dramatização humorística da escrita romanesca, evocando Valêncio Xavier, Leminski e Agrippino" (SUSSEKIND, 2013, [s.p.]). Certamente que isso acontece, mas, a meu ver, é pena que a evocação não tenha sido crítico-humorística.

\section{Referências}

ANDRADE, Oswald. Obras completas II: Memórias sentimentais de João Miramar Serafim Ponte Grande. Rio de Janeiro: Civilização Brasileira, 1978.

BOPP, Raul. Putirum poesias e coisas do folclore. Rio de Janeiro: Editora Leitura S.A, 1968.

BOPP, Raul. Vida e morte da antropofagia (recurso eletrônico). Rio de Janeiro: José Olympio, 2012. (Sabor Literário recurso digital)

COMPAGNON, Antoine. O trabalho da citação. Trad. Cleonice P. B. Mourão. Belo Horizonte: Editora UFMG, 1996.

DRUMMOND, Carlos de Andrade. Obra completa em um volume. Rio de Janeiro: Companhia José Aguilar Ed., 1967. 
EAGLETON, Terry. "Capitalismo, modernismo e pós-modernismo". Trad. João Roberto Martins Filho. Rev.téc. Tania Pellegrini. Crítica marxista. São Paulo, Brasiliense, v. 1, n. 2, p. 53-68, 1995.

HOLANDA, Sérgio Buarque de. O espírito e a letra Estudos de crítica literária II 1948-1959. Org., introdução e notas Antonio Arnoni Prado. São Paulo: Companhia das Letras, 1996.

JAMESON, Fredric. Pós-Modernismo A lógica cultural do capitalismo tardio. Trad. Maria Elisa Cevasco. Rev. da Tradução. Iná Camargo Costa. São Paulo: Ática, 1996.

SAFATLE, Vladimir. Cinismo e falência da crítica. São Paulo: Boitempo, 2008.

SANTIAGO, SILVIANO. "O começo do fim”. Gragoatá, Niterói, n. 24, p. 13-30, $1^{\circ}$ sem., 2008.

STIGGER, Veronica. Opisanie Swiata. São Paulo: Cosac Naify, 2013. 